\title{
Analysis of the effects of hyperbaric gases on S. cerevisiae cell cycle through a morphological approach
}

\author{
M.A.Z. Coelho ${ }^{\text {a,* }}$, J.A.P. Coutinho ${ }^{\text {b }}$, E.C. Ferreira ${ }^{c}$, M. Mota ${ }^{c}$, I. Belo ${ }^{c}$ \\ ${ }^{a}$ Departamento de Engenharia Bioquímica, Escola de Química/UFRJ, 21949-900 Rio de Janeiro, Brazil \\ ${ }^{\mathrm{b}}$ CICECO, Departamento de Química, Universidade de Aveiro, Aveiro, Portugal \\ ${ }^{\mathrm{c}}$ IBB_-Institute for Biotechnology and Bioengineering, Centre of Biological Engineering, Universidade do Minho, \\ Campus de Gualtar, 4710-057 Braga, Portugal
}

Received 27 December 2006; received in revised form 25 April 2007; accepted 5 July 2007

\begin{abstract}
The effects of hyperbaric gases on the cell cycle of Saccharomyces cerevisiae were studied in batch cultures under pressures between 0.1 and $0.6 \mathrm{MPa}$ and different gas compositions (air, oxygen, nitrogen or carbon dioxide). Classification of S. cerevisiae cells based on their morphology stages was obtained using an automatic image analysis procedure. Information on the distribution of different sub-populations along the cell cycle is reported. A structured morphological model was developed and used to describe the measured data. The results herein reported demonstrate that the bud separation phase is the limiting step in cell duplication. Additionally, the influence of the environmental conditions, specially the oxygen partial pressure, on the START event is reported. Under anaerobic conditions, no significant influence of hyperbaric gases on the cell cycle was verified.
\end{abstract}

(C) 2007 Elsevier Ltd. All rights reserved.

Keywords: Cell cycle; Saccharomyces cerevisiae; Hyperbaric conditions; Digital image analysis; Morphology

\section{Introduction}

Although a general agreement exists that cell growth and division are functionally coordinated, the mechanisms that link these two processes are poorly understood [1]. The basic mechanisms for cell cycle control seem to be similar in eukaryotic organisms and are mainly based on size control, i.e. there is a critical size for DNA replication and cell division $[2,3]$.

Saccharomyces cerevisiae and Schizosaccharomyces pombe are simple yet powerful organisms generally used in studies of eukaryotic cell cycle [4-10]. The cell cycle compromises a succession of discrete events subjected to complex genetic regulations.

S. cerevisiae cell division initially involves a protuberance development, called bud, that begins with the START event or S phase related to plaque duplication and separation (Fig. 1). The bud formation is the visible evidence that the cell passes the START event and is followed by nuclear migration at $\mathrm{G}_{2}$ phase

\footnotetext{
* Corresponding author. Tel.: +55 21 25627572; fax: +55 2125627622

E-mail address: mcoelho@dq.ua.pt (M.A.Z. Coelho).
}

and spindle elongation and nuclear division at $\mathrm{M}$ phase. The limiting step for cell cycle progression is related to protein synthesis. The bud detachment occurs along $G_{1}$ phase and a new cell is born. Daughter cells are not able to enter in a division process until they have reached a critical size (around $35 \mu^{3}$ for haploid wild-type cells in rich medium) and become adult cells [11].

This size control of the cell cycle consists of two components: a 'sizer' phase, which is the time for the cell to reach the critical size, followed by a 'timer' phase, which is nearly independent of cell size. Thus, cells that are born larger than the critical size have an almost constant cycle time, regardless of their birth size. For cells born below the critical size, the cycle time lengthens as birth sizes decrease due to the influence of the sizer phase [1].

Due to the heterogeneity of $S$. cerevisiae population, its culture in a bioreactor comprises a large group of cells that are able to bud and also daughter cells, all of them exposed to the same environmental conditions, but carrying distinct metabolic reactions according to its own intrinsic characteristics. Small variations of phenotypical properties among cells may incur in interferences on gene expression, malfunction of a genetic 


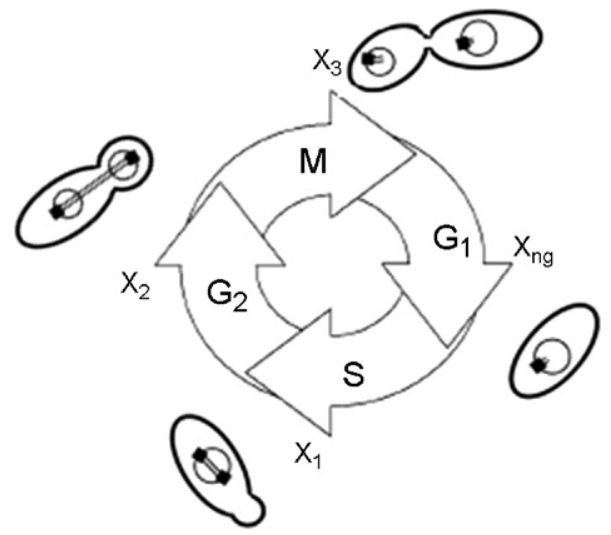

Fig. 1. Schematic diagram for cell morphological changes used in cell cycle description ( $S$ phase plaque duplication; $G_{2}$ phase: nuclear migration; $M$ phase: nuclear division; $G_{1}$ phase: bud detachment).

mechanism or metabolic reactions network, among other events. This heterogeneity may be due to inherent genetic discrepancies, environmental externalities, combination of both factors and chance. Many of these biological processes are yet not fully understood and/or involve phenomena that are very difficult to observe and measure [12].

It is a common practice to describe the behavior of a microbial population under known (or controlled) environmental conditions through mathematical models that lump all cells into an abstraction traditionally called "biomass", i.e. a large group of heterogeneous cells quantified by its total mass. Segregation of the population due to cell division is a quite difficult task at a reactor scale. Flow cytometry is usually employed to monitor sub-populations according to their DNA or protein content $[8,13]$. Cell physiological and morphological analysis may also be performed through digital image procedures [14-16] that may envisage the mechanisms behind the cell cycle effect and also distinguish mutants that are altered in their response to the environmental conditions, like gas pressure increase.

Many differences found between laboratory and industrial behavior can be partially explained by the different environmental conditions achieved in each system. Due to the large scale of industrial reactors and consequently the differences observed in the residence time distribution, cells are distinctly exposed to total pressure conditions and to dissolved gas concentration, that are a function of the local position in the reactor. This is particularly important when gas solubility is a determinant factor in a process, as is the case of oxygen solubility in high-cell-density aerobic cultures and carbon dioxide in large-scale fermentations. Moreover, air pressure increase has been proven to be an effective way of oxygen transfer rate enhancement in cell cultures $[17,18]$. However, limits of pressure increase were found due the oxidative stress caused to the cells by hyperbaric oxygen [19]. As a consequence, analysis of pressure effects in cell physiology and morphology must be considered.

This work deals with the study of $S$. cerevisiae cell cycle under pressures between 0.1 and $0.6 \mathrm{MPa}$ and different gases (air, oxygen, nitrogen or carbon dioxide). Morphological information was obtained through a digital image procedure. A structured model was developed to describe the biomass at different cell cycle stages. The model was formulated based on a series of consecutive reactions describing the yeast morphological changes along the cell cycle from the protuberance appearance till the bud detachment, integrating the discrete events of the cell cycle.

\section{Materials and methods}

\subsection{Experimental conditions}

The experimental conditions herein used to analyze the cell cycle behavior and postulate the model formulation were identical to those described in Coelho et al. [15]. Cells of $S$. cerevisiae ATCC 32167 were cultured in a medium composed by $0.4 \mathrm{~g} \mathrm{~L}^{-1} \mathrm{MgSO}_{4} \cdot 7 \mathrm{H}_{2} \mathrm{O}, 2.0 \mathrm{~g} \mathrm{~L}^{-1}\left(\mathrm{NH}_{4}\right)_{2} \mathrm{SO}_{4}, 5.0 \mathrm{~g} \mathrm{~L}^{-1}$ $\mathrm{KH}_{2} \mathrm{PO}_{4}, 1.0 \mathrm{~g} \mathrm{~L}^{-1}$ yeast extract, $5.0 \mathrm{~g} \mathrm{~L}^{-1}$ glucose (pH was adjusted to 4.0 prior autoclaving). For batch cultivation, a $600-\mathrm{mL}$ stainless steel reactor (Parr 4563) at a temperature of $30{ }^{\circ} \mathrm{C}$ and at a stirring rate of $400 \mathrm{rpm}$ was used. Compressed pure gas (air, $\mathrm{O}_{2}, \mathrm{~N}_{2}$ or $\mathrm{CO}_{2}$ ) was continuously sparged into the culture medium at $1 \mathrm{~L} \mathrm{~min}^{-1}$ (measured at standard conditions of temperature and pressure). The initial yeast concentration was $0.2 \mathrm{~g} \mathrm{~L}^{-1}$ and the total batch time was around $7 \mathrm{~h}$

More details about the analytical methods employed for the quantification of glucose (through 3,5-dinitrosalycilic acid method), ethanol (quantified by HPLC) and cell (dry weight at $620 \mathrm{~nm}$ ) concentrations can be found in Coelho et al. [15].

\subsection{Image analysis procedure}

The image acquisition and treatment procedures had been previously described by Coelho et al. [15] and were developed with Matlab v. 6.1 (The Mathworks Inc.) package.

Feature extraction and object separation were necessary to classify "mothers" and "daughters" and to determine their frequency in the analyzed samples. Initially, objects were labeled permitting to extract individual properties (area, equivalent diameter, major axis length, minor axis length and orientation, among others). Assuming that the cell projection onto the image is an ellipse, a parameter called "elongation" (major axis length/minor axis length) was computed according to Pons and Vivier [14] to discriminate nonbud from bud cells.

For detected bud cells, the image was cropped according to cell orientation (the angle between the $x$-axis and the ellipse major axis) and mother and daughter cells were separated employing the watershed algorithm. After bud separation, its area was characterized as a function of the whole cell area and objects were divided in four classes according to different morphological stages (Fig. 1): single cells (without any detectable protuberance, $\mathrm{G}_{1}$ phase), growing cells with buds size between 0 and $20 \%$ (entrance in $\mathrm{G}_{2}$ phase), 20 and $30 \%$ (transition to $\mathrm{M}$ phase), and 30 and $50 \%$ (end of $\mathrm{M}$ phase) of the whole cell (mother and bud) area, since the bud will detach from the mother with a size near to the mother size. The different $S$. cerevisiae sub-populations used in the model formulation were then obtained according to this image analysis procedure.

This procedure allowed evaluating 250-500 cells in each sample leading to an average error smaller than $5 \%$ for number of total objects and a correction factor of about $14 \%$ when large numbers of bud cells are determined.

\subsection{Model formulation}

The model proposed for the cell cycle description takes into account the consecutive stages that naturally occur during bud development, i.e. it is a segregated model based on cell morphology (Fig. 1). The cell cycle was divided in four phases with respect to the protuberance appearance till bud separation. The different sub-populations in S. cerevisiae batch culture were distinguished as follows: 


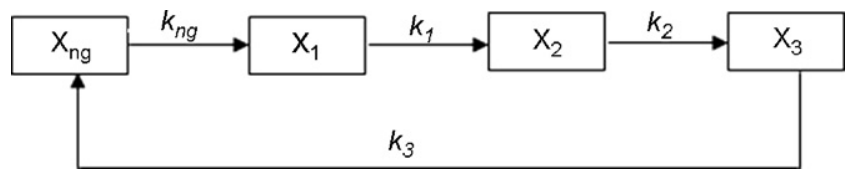

Fig. 2. Block diagram used for the model development: cell cycle as a sequence of reactions.

- cells with bud between 0 and $20 \%$ of the whole cell size $\left(X_{1}\right)$;

- cells with bud between 20 and $30 \%$ of the whole cell size $\left(X_{2}\right)$;

- cells with bud between 30 and $50 \%$ of the whole cell size $\left(X_{3}\right)$ and

- single cells $\left(X_{\mathrm{ng}}\right)$, consisting of mother cells and daughter cells waiting to reach the critical size for duplication.

Thus, the total number of cells $\left(X_{\mathrm{T}}\right)$ can be obtained through the following equation:

$X_{\mathrm{T}}=X_{1}+X_{2}+X_{3}+X_{\mathrm{ng}}$

A Monod-type model was used to describe the cell growth rate in all budding stages and the mass balances for each growth phase are based on the approach to the description of consecutive reactions, i.e. the product of one reaction becoming the reactant in the next one [20], as displayed in Fig. 2.

The start of the cell cycle is dependent on the environmental conditions, in particular, on the substrate concentration. Coelho et al. [15] described the influence of glucose consumption rate on bud cell percentage: Experimental conditions with high substrate consumption rates lead to a decrease in bud cell percentage. In this model this dependence is considered as $S^{\alpha}$, displaying distinct behaviors according to the $\alpha$ value. The model is, thus, composed by six ordinary differential equations (ODEs) relating the kinetic rates for cell growth in different stages of reproduction, substrate consumption and product formation for a batch system, as described by

$\frac{\mathrm{d} X_{1}}{\mathrm{~d} t}=\left(1-k_{1}\right) \mu X_{1}+k_{\mathrm{ng}} S^{\alpha} X_{\mathrm{ng}}$

$\frac{\mathrm{d} X_{2}}{\mathrm{~d} t}=\left(1-k_{2}\right) \mu X_{2}+k_{1} \mu X_{1}$

$\frac{\mathrm{d} X_{3}}{\mathrm{~d} t}=\left(1-k_{3}\right) \mu X_{3}+k_{2} \mu X_{2}$

$\frac{\mathrm{d} X_{\mathrm{ng}}}{\mathrm{d} t}=k_{3} \mu X_{3}+\mu X_{\mathrm{ng}}-k_{\mathrm{ng}} S^{\alpha} X_{\mathrm{ng}}$

$\frac{\mathrm{d} S}{\mathrm{~d} t}=-Y_{S / X} \mu X_{\mathrm{T}}$

$\frac{\mathrm{d} P}{\mathrm{~d} t}=Y_{P / X} \mu X_{\mathrm{T}}$

where $\mu=\mu_{\max }\left(S / K_{S}+S\right)$.

The solution of the system of ordinary differential equations was performed using Matlab v. 6.1 (The Mathworks Inc.). The implicit 3rd order Runge-Kutta method for non-stiff ODEs was applied to find the solution of the system. Values for $k_{1}, k_{2}, k_{3}, k_{\mathrm{ng}}, \alpha$ parameters were estimated by means of least squares approach using the Nelder-Mead Simplex optimization method. To minimize the number of parameters to estimate, the values of $\mu_{\max }$ and $K_{S}$ were obtained from data regression $\left(X_{\mathrm{T}}, P\right.$ and $\left.S\right)$ using the non-structured Monod-model for

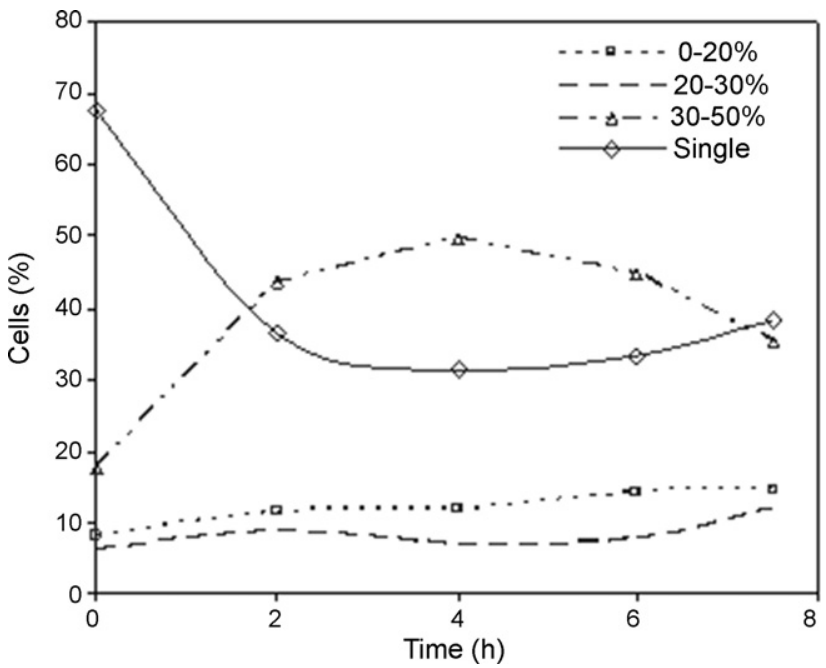

Fig. 3. Budding formation and growth along $S$. cerevisiae cell cycle in atmosphere of air at $0.1 \mathrm{MPa}$, considering single cells and growing cells (size buds between 0 and 20\%, 20 and 30\%, and 30 and 50\% of the whole cell area).

each experimental condition. The yields, namely $Y_{S / X}$ and $Y_{P / X}$, were directly calculated from the experimental data as average values over a given fermentation.

\section{Results and discussions}

A Monod-model type was used to describe the traditional $X-$ $P-S$ evolution along a $S$. cerevisiae batch cultivation carried out in a hyperbaric reactor. The Monod kinetic parameters $\mu_{\max }$ and $K_{S}$ were estimated for each condition studied from the experimental data and are presented in Table 1. $Y_{S / X}$ and $Y_{P / X}$, previously reported in Coelho et al. [15], are here included since these yield parameters were used in the solution of the proposed model, i.e. in the model parameters estimation. The authors showed that the effect of pressure up to $0.6 \mathrm{MPa}$ on cell metabolism strongly depends on the nature of the gas used for pressurization. Under aerobic conditions oxygen toxicity, and not the total pressure itself, is the major cause of cell damage. Moreover, the influence of hyperbaric $\mathrm{N}_{2}$ on the fermentation process is not as deleterious as the $\mathrm{CO}_{2}$.

The effects of hyperbaric gases on the cell cycle of $S$. cerevisiae were analyzed through a structured model, which describes the morphological changes observed along cell duplication. These morphological changes were followed during a fermentation using a digital image analysis procedure,

Table 1

Effect of gas pressure on the substrate to cell mass yield, $Y_{S / X}$, product (ethanol) to biomass yield, $Y_{P / X}$, maximum specific cell growth rate, $\mu_{\text {max }}$ and substrate saturation constant, $K_{S}$, for batch cultivation of $S$. cerevisiae

\begin{tabular}{|c|c|c|c|c|c|c|c|c|}
\hline \multirow[t]{2}{*}{ Gas pressure (MPa) } & \multicolumn{2}{|l|}{ Air } & \multicolumn{2}{|l|}{$\mathrm{O}_{2}$} & \multicolumn{2}{|l|}{$\mathrm{N}_{2}$} & \multicolumn{2}{|l|}{$\mathrm{CO}_{2}$} \\
\hline & 0.1 & 0.6 & 0.3 & 0.5 & 0.1 & 0.6 & 0.1 & 0.6 \\
\hline$Y_{S / X}\left(\mathrm{~g} \mathrm{~g}^{-1}\right)$ & 3.45 & 4.00 & 7.14 & 25.00 & 6.25 & 5.26 & 6.67 & 20.00 \\
\hline$Y_{P / X}\left(\mathrm{~g} \mathrm{~g}^{-1}\right)$ & 1.41 & 1.40 & 0.29 & 0.00 & 2.25 & 2.74 & 2.00 & 3.40 \\
\hline$\mu_{\max }\left(\mathrm{h}^{-1}\right)$ & $0.43 \pm 0.0011$ & $0.64 \pm 0.0419$ & $0.18 \pm 0.0423$ & $0.03 \pm 0.0041$ & $0.37 \pm 0.0013$ & $0.33 \pm 0.0080$ & $0.37 \pm 0.0026$ & $0.07 \pm 0.0035$ \\
\hline$K_{\mathrm{S}}\left(\mathrm{g} \mathrm{L}^{-1}\right)$ & $1.21 \pm 0.0015$ & $3.73 \pm 0.0867$ & $1.60 \pm 0.0622$ & $1.95 \pm 0.0058$ & $1.26 \pm 0.0018$ & $1.28 \pm 0.0113$ & $1.26 \pm 0.0039$ & $1.94 \pm 0.0487$ \\
\hline
\end{tabular}

Data are means of two independent replicates.

Considering a $95 \%$ confidence interval. 
Table 2

Influence of the gas pressure and composition on the estimated parameters of the morphological structured model

\begin{tabular}{|c|c|c|c|c|c|c|c|c|}
\hline \multirow{2}{*}{$\begin{array}{l}\text { Gas } \\
\text { pressure (MPa) }\end{array}$} & \multicolumn{2}{|l|}{ Air } & \multicolumn{2}{|l|}{$\mathrm{O}_{2}$} & \multicolumn{2}{|l|}{$\mathrm{N}_{2}$} & \multicolumn{2}{|l|}{$\mathrm{CO}_{2}$} \\
\hline & 0.1 & 0.6 & 0.3 & 0.5 & 0.1 & 0.6 & 0.1 & 0.6 \\
\hline$k_{1}$ & $2.10 \pm 0.0004$ & $4.43 \pm 0.0017$ & $3.82 \pm 0.0004$ & $19.49 \pm 0.0044$ & $1.59 \pm 0.0007$ & $1.68 \pm 0.0113$ & $1.76 \pm 0.0032$ & $4.42 \pm 0.0012$ \\
\hline$k_{2}$ & $2.14 \pm 0.0015$ & $7.06 \pm 0.0022$ & $3.72 \pm 0.0335$ & $34.66 \pm 0.0053$ & $3.51 \pm 0.0010$ & $3.00 \pm 0.0186$ & $4.25 \pm 0.0080$ & $6.83 \pm 0.0016$ \\
\hline$k_{3}$ & $0.48 \pm 0.0018$ & $4.34 \pm 0.0055$ & $0.09 \pm 0.0283$ & $1.51 \pm 0.0122$ & $3.31 \pm 0.0030$ & $2.28 \pm 0.0112$ & $0.68 \pm 0.0069$ & $3.56 \pm 0.0117$ \\
\hline$k_{\mathrm{ng}}$ & $0.15 \pm 0.0031$ & $0.29 \pm 0.0119$ & $0.36 \pm 0.0289$ & $0.66 \pm 0.0290$ & $0.08 \pm 0.0056$ & $0.07 \pm 0.0188$ & $0.13 \pm 0.0034$ & $0.35 \pm 0.0361$ \\
\hline$\alpha$ & $0.20 \pm 0.0024$ & $1.91 \pm 0.0024$ & $0.22 \pm 0.0195$ & $0.51 \pm 0.0163$ & $1.57 \pm 0.0015$ & $1.53 \pm 0.0544$ & $1.28 \pm 0.0012$ & $0.53 \pm 0.0183$ \\
\hline
\end{tabular}

Considering a $95 \%$ confidence interval.

generating data such as those shown in Fig. 3 for the batch growth in the presence of air at $0.1 \mathrm{MPa}$. This growth profile shows that the limiting step in cell duplication may lie in its latter phase, near the cell separation step, when the bud size is about $30-50 \%$ of the whole budding cell size. Additionally, it is experimentally verified that only a fraction of the adult cells will enter mitosis, in agreement with the suggestion reported in Duboc and von Stockar [21].

The parameter identification of the structured model provided values for the constant rates presented in Table 2 . Typical behaviors are shown in Fig. 4a and b for an aerobic
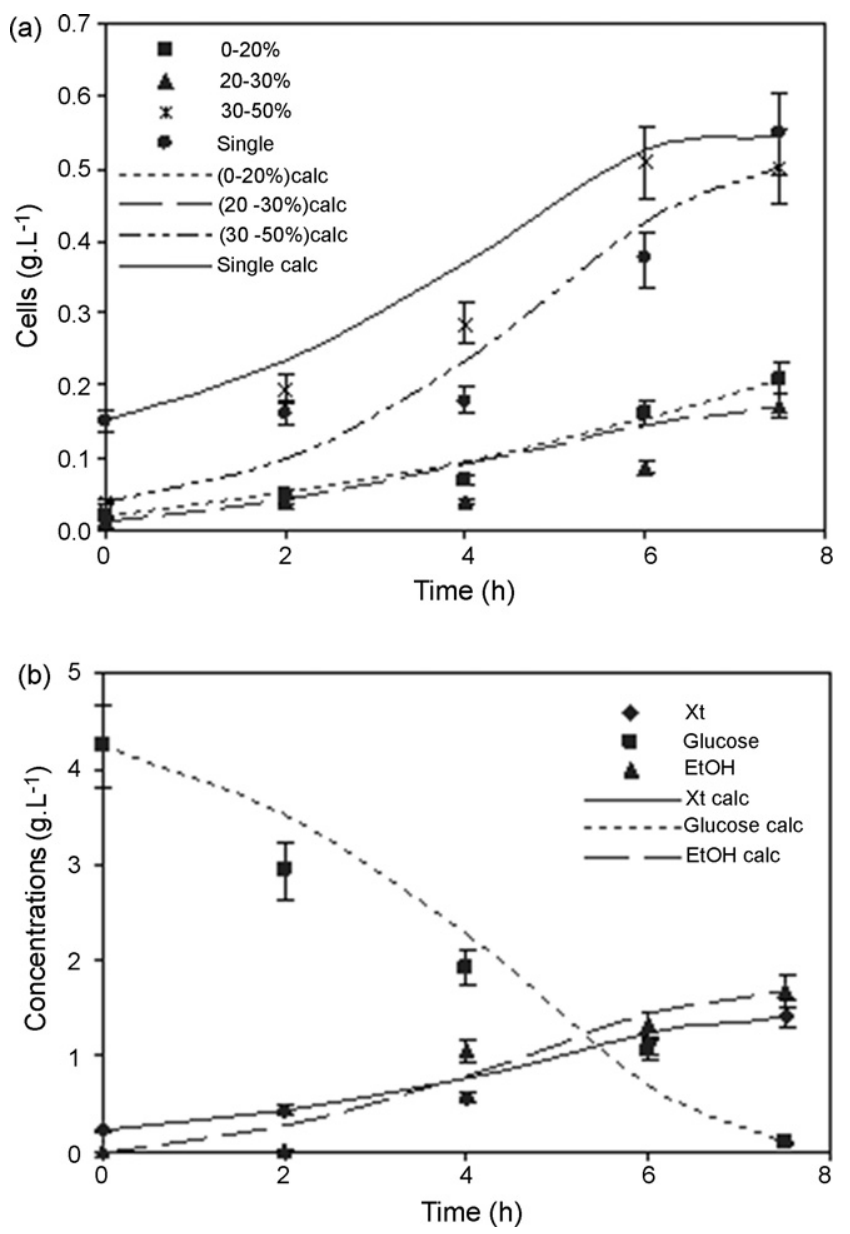

Fig. 4. Experimental data and description of the morphological structured model for air at 0.1 MPa. (a) Biomass at different stage of the cell cycle (single cells, cells with bud between 0 and $20 \%, 20$ and $30 \%$, and 30 and $50 \%$ of the whole cell size); (b) concentrations profiles along batch $\left(X_{\mathrm{T}}\right.$ : total biomass, glucose and ETOH: ethanol). system (air at $0.1 \mathrm{MPa}$ ) and Fig. 5a and $\mathrm{b}$ for an anaerobic one $\left(\mathrm{CO}_{2}\right.$ at $\left.0.1 \mathrm{MPa}\right)$. Since the obtained $k_{2}$ values are greater or at least equal to $k_{1}$ values, is possible to assure that the cell cycle "clock" does not present any delay in this cycle phase, when the size of the bud is between 0 and $20 \%$ of the whole budding cell size. This result indicates that plaque separation and nuclear migration are not the limiting step in S. cerevisiae cell cycle.

The $k_{3}$ values reported in Table 2 demonstrate the great influence of this phase on the overall cell cycle. Atmospheres with pure oxygen, with both 0.3 and $0.5 \mathrm{MPa}$, seem to
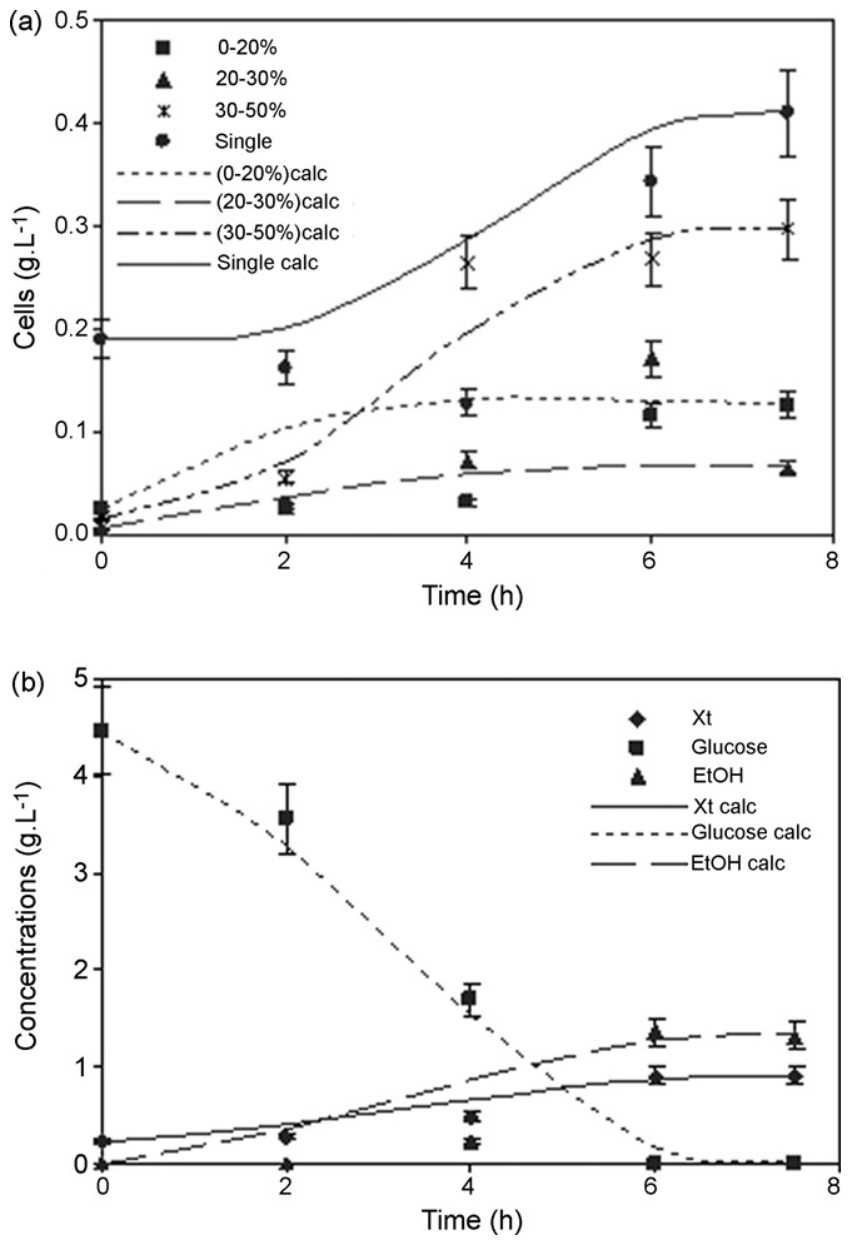

Fig. 5. Experimental data and description of the morphological structured model for $\mathrm{CO}_{2}$ at $0.1 \mathrm{MPa}$. (a) Biomass at different stage of the cell cycle (single cells, cells with bud between 0 and $20 \%, 20$ and $30 \%$, and 30 and $50 \%$ of the whole cell size); (b) concentrations profiles along batch $\left(X_{\mathrm{T}}\right.$ : total biomass, glucose and ETOH: ethanol). 
decelerate the cycle in this phase as indicated by the low $k_{3} / k_{2}$ ratio (0.02 and 0.04 , respectively) showing that cells grown in an oxidative atmosphere delay the bud detachment. As previously discussed, it seems that, under aerobic conditions, oxygen toxicity is the major cause of cell damage imposing a drastic cell inhibition under pure oxygen atmosphere due to oxidative stress mechanisms [19,22,23]. A different behavior is observed for systems at 0.1 and $0.6 \mathrm{MPa}$ with air (0.02-0.12 MPa of oxygen partial pressure). Higher values for $k_{3} / k_{2}$ ratio are obtained when the oxygen partial pressure increases indicating that, in an aerobic atmosphere, a decrease of bud separation time may occur. There seems to be an optimum partial pressure for oxygen that minimizes the time spent on the $\mathrm{M}$ phase where the benefits of a richer aeration are not offset by the oxidative stress.

The $k_{\mathrm{ng}}$ values obtained for aerobic atmospheres (air at 0.1 and at 0.6 MPa) indicate a considerable influence of the pressure on this parameter (two-fold higher) that is the rate constant related to the start of the cell cycle. Higher $k_{\mathrm{ng}}$ values lead to lower times at $\mathrm{G}_{1}$ phase as observed at higher pressures under aerobic conditions. In the same direction, the dependence of the glucose consumption on budding cells, herein expressed by $\alpha$ parameter, indicates that pressure exerts a considerable influence in the substrate used for cells duplication under aerobic conditions.

The effects noticed in the cell cycle "clock" - decrease in bud separation time and smaller $G_{1}$ phase - may be related to the oxygen availability. It is well known that the $\mathrm{G}_{1}$ period of the cell cycle is the most sensitive to growth conditions. The combined length of the cell cycle periods $\mathrm{S}$ (plaque duplication and separation), $G_{2}$ (nuclear migration and spindle elongation) and $\mathrm{M}$ (cell separation) generally remains constant independently of the specific growth rate, indicating that some event in $\mathrm{G}_{1}$ phase may control the cell cycle length under different environmental conditions $[21,24]$.

Metabolically, the lengthening of $\mathrm{G}_{1}$ phase has been associated with low glucose fluxes, high levels of respiratory enzymes and repressed levels of glycolytic enzymes. Moreover, mitochondria are essential organelles to perform fundamental cellular functions including aerobic energy mobilization and fatty acid oxidation, among others, and cannot be synthesized de novo. Boldogh et al. [25] indicated that the inheritance of this organelle and the pattern of mitochondrial distribution are closely linked to the cell cycle, as daughter cells that do not inherit mitochondria will not survive. Since most of the biochemical pathways related to cell division are oxygen dependent, the influence of hyperbaric air improving the oxygen transfer rate plays an important role for cell cycle development. Such considerations support the behavior observed in this work in what concerns the great influence of the environmental conditions, specially the oxygen partial pressure, on the constant rate related to the beginning of the START event.

Under anaerobic conditions, no significant differences were obtained at 0.1 or $0.6 \mathrm{MPa}$ of nitrogen with respect to the cell cycle clock, since similar $k$ values were achieved for both systems. Considering the lower $k_{\text {ng }}$ values presented in Table 2 for experiments under nitrogen atmosphere, it is possible to denote a change in the cell cycle "clock" under such conditions since a lower number of cells will enter in $\mathrm{S}$ phase to initiate its duplication. This behavior is somehow explained by the $S$. cerevisiae metabolism [24]. Additionally, Coelho et al. [15] described that an increase in $\mathrm{N}_{2}$ pressure to $0.6 \mathrm{MPa}$ stimulated the fermentative activity of the cells, since an increase of ethanol yield was found. Nevertheless, the increase of $\mathrm{CO}_{2}$ pressure in the same range reduced cell growth (Table 1), a behavior in anaerobic conditions similar to that described to oxygen, since cell cycle is strongly affected by $0.5 \mathrm{MPa} \mathrm{O}_{2}$ and $0.6 \mathrm{MPa} \mathrm{CO}_{2}$ pressures. The effects of high-pressure oxygen and carbon dioxide on cell division may not be comparable and differences were also detected on cell morphology, since a decrease of the average cell size was found for cells exposed to $0.6 \mathrm{MPa} \mathrm{CO}$, as previously reported by Coelho et al. [15]. It is well known that high-pressure $\mathrm{CO}_{2}$ is an effective means of cell inactivation [26,27], keeping the cells in lag phase.

\section{Conclusions}

The structured model describing the $S$. cerevisiae cell cycle as reactions in sequence leads to a good description of the morphological experimental data, being a useful tool in the study of different hyperbaric environmental conditions on yeast cell cycle development. From the results obtained through morphological image analyses, the cell separation step (when the bud size is about $30-50 \%$ of the whole budding cell size) may be considered the limiting step in cell duplication. The influence of the environmental conditions, specially the oxygen partial pressure, on the constant rate related to the beginning of the START event was related to the oxygen availability, giving a decrease in bud separation time and lower $\mathrm{G}_{1}$ phase within the pressure raise. Under anaerobic conditions, no significant differences were verified, demonstrating that the nature of the gas is crucial for the yeast cell cycle development and not the total pressure itself.

\section{Acknowledgments}

M.A.Z. Coelho thanks Prof. John Villadsen (DTU) for the fruitful discussion concerning to the results of this paper. Financial support from CAPES/GRICES, CNPq (Brazil) and FCT (Portugal) are gratefully acknowledged.

\section{Appendix A. Nomenclature}

$k_{\text {ng }} \quad$ constant rate for $X_{\text {ng }}$ into $X_{1}$ conversion

$k_{1} \quad$ constant rate for $X_{1}$ into $X_{2}$ conversion

$k_{2} \quad$ constant rate for $X_{2}$ into $X_{3}$ conversion

$k_{3} \quad$ constant rate for $X_{3}$ into $X_{\text {ng }}$ conversion

$K_{S} \quad$ substrate saturation constant $\left(\mathrm{g} \mathrm{L}^{-1}\right)$

$P \quad$ product (ethanol) concentration $\left(\mathrm{g} \mathrm{L}^{-1}\right)$

$P_{\mathrm{R}} \quad$ pressure (MPa)

$S \quad$ substrate (glucose) concentration $\left(\mathrm{g} \mathrm{L}^{-1}\right)$

$t \quad$ time (h)

$X_{\mathrm{ng}} \quad$ non-budding cells concentration $\left(\mathrm{g} \mathrm{L}^{-1}\right)$ 
$X_{\mathrm{T}} \quad$ total cell concentration $\left(\mathrm{g} \mathrm{L}^{-1}\right)$

$X_{1} \quad$ cells concentration with bud size between 0 and $20 \%$ of the budding cell area $\left(\mathrm{g} \mathrm{L}^{-1}\right)$

$X_{2} \quad$ cells concentration with bud size between 20 and $30 \%$ of the budding cell area $\left(\mathrm{g} \mathrm{L}^{-1}\right)$

$X_{3} \quad$ cells concentration with bud size between 30 and $50 \%$ of the budding cell area $\left(\mathrm{g} \mathrm{L}^{-1}\right)$

$Y_{P / X} \quad$ product to biomass yield coefficient $\left(\mathrm{g} \mathrm{g}^{-1}\right)$

$Y_{S / X} \quad$ substrate to biomass yield coefficient $\left(\mathrm{g} \mathrm{g}^{-1}\right)$

\section{Greek letters}

$\alpha \quad$ parameter related to the influence of substrate concentration on budding occurrence

$\mu_{\max } \quad$ maximum specific growth rate $\left(\mathrm{h}^{-1}\right)$

\section{References}

[1] Qu Z, Weiss JN, MacLellan WR. Coordination of cell growth and cell division: a mathematical modeling study. J Cell Sci 2004;117:4199-207.

[2] Hartwell LH, Unger MW. Unequal division in Saccharomyces cerevisiae and its implications for the control of cell division. J Cell Biol 1977;75:422-35.

[3] Sveiczer A, Novak B, Mitchison JM. The size control of fission yeast revisited. J Cell Sci 1996;109:2947-57.

[4] Fantes PA. Control of cell size and cycle time in Schizosaccharomyces pombe. J Cell Sci 1977;24:51-67.

[5] Nurse P, Thuriaux P. Controls over the timing of DNA replication during the cell cycle of fission yeast. Exp Cell Res 1977;107:365-75.

[6] Mitchison JM, Nurse P. Growth in cell length in the fission yeast Schizosaccharomyces pombe. J Cell Sci 1985;75:357-76.

[7] Carter BL, Jagadish MN. The relationship between cell size and cell division in the yeast Saccharomyces cerevisiae. Exp Cell Res 1978;112:15-24.

[8] Münch T, Sonnleitner B, Fiechter A. The decisive role of the Saccharomyces cerevisiae cell cycle behaviour for dynamic growth characterization. J Biotechnol 1992;22:329-52.

[9] Srienc F, Dien BS. Kinetics of the cell cycle of Saccharomyces cerevisiae. Ann NY Acad Sci 1992;665:59-71.

[10] Dien BS, Peterson MS, Srienc F. Cell-cycle analysis of Saccharomyces cerevisiae. Methods Cell Biol 1994;42:457-75.

[11] Creator J, Joyne J. In: Fantes P, Brooks R, editors. The cell cycle-a practical approach. USA: IRL Press; 1993. p. 69-92.
[12] Duarte MVE, Medeiros JL, Araújo OQF, Coelho MAZ. An age-structured population balance model for microbial dynamics. Braz J Chem Eng 2003;20:1-6.

[13] Alberghina L, Porro D. Quantitative flow cytomery: analysis of protein distribution in budding yeast: a mini-review. Yeast 1993;9:815-23.

[14] Pons MN, Vivier H. Morphometry of yeast. In: Wilkinson MHF, Schut F, editors. Digital image analysis of microbes: imaging, morphometry, fluorometry and motility techniques and applications. England: John Wiley \& Sons; 1998. p. 199-224.

[15] Coelho MAZ, Belo I, Pinheiro R, Amaral AL, Mota M, Coutinho JAP, et al. Effect of hyperbaric stress on yeast morphology: study by automated image analysis. Appl Microbiol Biotechnol 2004;66:318-24.

[16] Coutinho JAP, Belo I, Ferreira EC, Coelho MAZ. Assessment of yeast viability under hyperbaric conditions through a modeling approach. $\mathrm{J}$ Chem Technol Biotechnol 2005;80:872-7.

[17] Belo I, Pinheiro R, Mota M. Fed-batch cultivation of Saccharomyces cerevisiae in a hyperbaric bioreactor. Biotechnol Prog 2003;19:665-71.

[18] Pinheiro R, Belo I, Mota M. Growth and $\beta$-galactosidase activity in cultures of Kluyveromyces marxianus under increased air pressure. Lett Appl Microbiol 2003;37:438-42.

[19] Belo I, Pinheiro R, Mota M. Morphological and physiological changes in Saccharomyces cerevisiae by oxidative stress from hyperbaric air. J Biotech 2005;115(4):397-404.

[20] Espenson JH. Consecutive reactions: the steady state and other approximations. In: Chemical kinetics and reaction mechanisms. USA: McGraw Hill; 1995. pp. 70-75.

[21] Duboc P, von Stockar U. Modeling of oscillating cultivations of Saccharomyces cerevisiae: identification of population structure and expansion kinetics based on on-line measurements. Chem Eng Sci 2000;55: 149-60.

[22] Pinheiro R, Belo I, Mota M. Oxidative stress response of Kluyveromyces marxianus to hydrogen peroxide, paraquat and pressure. Appl Microbiol Biotechnol 2002;58:842-7.

[23] Moradas-Ferreira P, Costa V, Piper P, Mager W. The molecular defenses against reactive oxygen species in yeast. Mol Microbiol 1996;19: 651-8.

[24] Anon MA, Mónaco ME, Cortassa S. Carbon and energetic uncoupling are associated with block division at different stages of the cell cycle in several cdc mutants of Saccharomyces cerevisiae. Exp Cell Res 1995;217:42-51.

[25] Boldogh IR, Fehrenbacher KL, Yang HC, Pon LA. Mitochondrial movement and inheritance in budding yeast. Gene 2005;354:28-36.

[26] Shimoda M, Cocunubo-Castellanos J, Kago H, Miyake M, Osajima Y, Hayakawa I. The influence of dissolved $\mathrm{CO}_{2}$ concentration on the death kinetics of Saccharomyces cerevisiae. J Appl Microbiol 2001;91: 306-11.

[27] Spilimbergo S, Elvassore N, Bertucco A. Microbial inactivation by highpressure. J Supercrit Fluid 2002;22:55-63. 